\title{
Abnormal Changes in the Glenoid Cavity of the Scapula
}

\author{
Swayam Jothi $S^{1}$, Jacintha Antony ${ }^{2}$, Usha Kannan ${ }^{3}$, Sujatha $\mathbf{N}^{4}$., Hemanth Kommuru ${ }^{5}$,, Rajeswara Rao $\mathrm{N}^{6}$ \\ ${ }^{1}$ Shri Sathya Sai Medical College \& Research Institute, Ammapettai \\ ${ }^{2}$ Balaji Medical College \& Hospital, Chrompet \\ ${ }^{3}$ Mahatma Gandhi Medical College \& Research Institute, Pondicherry \\ ${ }^{4,5,6}$ Shri Sathya Sai Medical College \& Research Institute, Ammapettai
}

\begin{abstract}
For frozen shoulder, the musculotendinous cuff \& supraspinatus tendinitis were commonly thought about. The status of the scapula and the articular surface of the glenoid cavity also can contribute this condition. Aim:To study the articular surface of the glenoid cavity. Materials \& Methods: 136 human scapulae (67 Right \& 69 Left) from SSSMCRI, MGMCRI \& Balaji Medical College were studied. The articular surface of the glenoid cavity and the vascular margins near its viscinity are studied.Observation:14 right scapulae showed osteophytic changes, 17 left scapulae showed osteophytic changes. Two of them presented deep rough area other than the articular area. Two of them presented separate articular facet, in one the entire articular surface was rough. Inference: Increased vascularity and more number of nutrient foraminae were observed in Scapulae showing osteophytic changes
\end{abstract}

Keywords: Glenoid cavity, Facet, Osteophytic changes

\section{Introduction}

Scapula is a triangular bone at the back of the chest with number of muscles taking origin and insertion. Has an important role in Abduction of shoulder above $90^{\circ}$ and elevating the shoulder provides additional protection to the thoracic cage from behind.Quite a number of articles have been published on the suprascapular notch, shape \& dimension of Glenoid cavity and coracoid process.

Glenoid cavity of scapula has variable morphology and therefore its anatomy is of enormous importance for orthopaedic surgeon and prosthetic designers. Presence of notch in the antero-superior part of glenoid rim affects the morphology of glenoid labrum. Anatomical variations of glenoid cavity are also important for understanding the various pathologies involving the shoulder joint.

\section{Aim}

To study the articular surface of the glenoid cavity

\section{Materials \& Methods}

136 human scapulae (67 Right \& 69 Left) from SSSMCRI, MGMCRI \& Balaji Medical College were studied. The articular surface of the glenoid cavity and the vascular margins near its viscinity are studied.

Inclusion Criteria- Scapula of proper shape

Exclusion Criteria - Scapulae showing unossified areas or some holes due to handling and wear \& tear.

\section{Observation}

Pear, comma, triangular \& oval Shapes of glenoid cavity were observed. The most common being comma shape. The length of the glenoid observed in the present study was varied from 30-38 mm. The AP glenoid diameter was 20-27 $\mathrm{mm}$.

17 right scapulae showed ostephytic changes, 14 left scapulae showed osteophytic changes. Two of them presented deep rough area (Fig: 1a \& 1b) other than the articular area. Two of them presented separate articular facet (Fig 2a \&2b), in one the entire articular surface was rough (Fig 3). Maximum length \& width of glenoid cavity observed was $38 \mathrm{~mm} \& 30 \mathrm{~mm}$ respectively (Fig:4). The smallest glenoid cavity had $27 \mathrm{~mm} \& 20 \mathrm{~mm}$ of length \& width respectively (Fig:5)

17 right scapulae showing osteophytic activity had the distribution of nutrient foraminae in the following manner

1. Presented one nutrient foramen in the neck, supraspinous fossa, 2 foraminae in the infraspinous fossa, one in the subscapular fossa and another near glenoid margin

2. Presented 2 foraminae at the root of coracoid process, one in the supraspinous fossa and 2 foraminae in the infraspinous fossa and 1 in the glenoid margin

3. Nutrient foramen at the neck, subscapular fossa and glenoid margin

4. Nutrient foramen at the neck, infraspinous fosssa and in the glenoid cavity

5. Presented nutrient foramen at the neck and supraspinous fossa

6. Nutrient foramen at the neck, supraspinous fossa and infra spinous fossa

7. Present 3 nutrient foraminae at supraspinous fossa, 3 foraminae at infraspinous fossa

8. Nutrient foramen at the neck and supraspinous fossa

9. Presented 2 nutrient foramen at the neck, suprascapular fossa and 3 in glenoid margin

10. Presented 2 nutrient foraminae at the neck, 1 in spraspinous fossa and 1 in infraspinous fossa 


\section{International Journal of Science and Research (IJSR) \\ ISSN (Online): 2319-7064}

Index Copernicus Value (2013): 6.14 | Impact Factor (2015): 6.391

11. Presented nutrient foramen at the neck and 3 foraminae at the glenoid margin

12. Nutrient foramen at the neck and 2 foraminae at the glenoid margin

13. Presented nutrient foramen in the supraspinous fossa, infraspinous fossa, glenoid margin and glenoid cavity

14. Nutrient foramen at the neck, supraspinous fossa, subscapular fossa and 4 in glenoid margin

15. Presented nutrient foramen at the neck, supraspinous fossa, subscapular fossa and 3 in glenoid margin

16. Presented nutrient foramen at the neck, supraspinous fossa, infraspinous fossa, subscapular fossa and 3 in glenoid margin.

17. Nutrient foramen at the neck, subscapular fossa and 2 in glenoid margin.

14 left scapulae showing osteophytic activity had the distribution of nutrient foraminae in the following manner

1. Nutrient foramen in the infraspinous fossa

2. Nutrient foramen in the neck

3. Nutrient foramen in the neck, supraspinous fossa, subscapular fossa and 2 in glenoid margin

4. Nutrient foramen at the neck, 3 in subscapular fossa and 2 in glenoid margin.

5. Nutrient foramen at the neck, glenoid margin and glenoid cavity

6. Nutrient foramen at the neck, supraspinous fossa and 2 in glenoid margin

7. Nutrient foramen at the neck. supraspinous fossa, infraspinous fossa and 2 in glenoid margin

8. Nutrient foramen at the neck, infraspinous fossa, subscapular fossa and 2 in glenoid margin

9. Presented 2 nutrient foraminae at the neck, 1 in infraspinous fossa and 2 in glenoid margin

10. Nutrient foramen at the neck, supraspinous fossa, infraspinous fossa and in glenoid margin

11. Nutrient foramen at the neck, supraspinous fossa, infraspinous fossa and in glenoid margin

12. Presented nutrient foramen at the neck and 2 in glenoid margin

13. Presented nutrient foramen at the neck and in glenoid margin

14. Presented nutrient foramen at the neck and in infraspinous fossa

\begin{tabular}{|c|c|c|}
\hline No of nutrient foramina & Rt side & Lt Side \\
\hline 7 & 2 & - \\
\hline 6 & 4 & 3 \\
\hline 5 & 2 & - \\
\hline 4 & 2 & 4 \\
\hline 3 & 4 & 1 \\
\hline 2 & 1 & 4 \\
\hline 1 & 2 & 2 \\
\hline
\end{tabular}

\section{Discussion}

The shape of the GC was found as inverted comma, pear, triangular and oval. The most common shape observed was of pear shaped GC in $69(56.09 \%)$ of 123 scapula.43 $(34.95 \%)$ were of inverted comma shape, $8(6.5 \%)$ of oval shape and $3(2.4 \%)$ were triangular [7]. In the present study comma shape, pear shape, oval shape \& triangular shape were observed the most common being comma shape.
The mean length of the glenoid observed in the present study was $38.78 \pm 3.03 \mathrm{~mm}$. The mean AP glenoid diameter 1 and 2 were $24.93 \pm 2.55 \mathrm{~mm}$ and $18.66 \pm 2.13 \mathrm{~mm}$ respectively [8]. In the present study the length of the glenoid observed in the present study was varied from $30-38 \mathrm{~mm}$. The AP glenoid diameter was $20-27 \mathrm{~mm}$.

The standard available smallest glenoid component in the market is $40 \mathrm{~mm}$ which may not fit the glenoid in present study population. This fact may be taken into consideration while designing glenoid prostheses for the Indian population. 31 scapulae showed osteophytic changes with more number of nutrient foramen \& vascular margins. Two of them presented deep rough area other than the articular area. Two of them presented separate articular facet, in one the entire articular surface was rough. Recently, Poppen et al (1976) emphasized that abnormal morphology of the glenoid is associated with severe full thickness tears [4], [5].

\section{Inference}

In frozen shoulder the musculotendinous cuff and supraspinatous tendinitis are commonly thought about. The status of the glenoid cavity also can contribute to this condition. In view of the above facts certain morphological features of the human scapula will be undertaken.

A precise knowledge of normal and variational anatomy of the glenoid cavity of the scapula is of great importance, in order to avoid complications when procedures are performed via open, arthroscopic, or arthroscopically assisted method adjoining shoulder region as well as for obtaining accurate congruency of the glenohumeral joint after total shoulder arthroplasty [1], [2], [4].

\section{References}

[1] Coskun N, Karoali K, Cevikol C, Demirel MB, Sindel M. Anatomical basis and variations of the scapula in Turkish adults.Saudi Medical Journal. 2006; 27(9): 1320-25.

[2] Wilk KE, Arrigo CA, Andrew JR. Currentconcepts: The stabilizing structures of Glenohumeral joint. Journal of Othropaedicand Sports physical therapy.1997; 25(6):36479

[3] Miles AEW. The glenoid notch and the shape of the glenoid cavity of the scapula. J Anat. 1997;191: 475

[4] Churchill RS, Brems JJ, Kotchi H. Glenoidsize, inclination, and version: an anatomic study. J Shoulder Elbow Surgery.2001;10:327-32

[5] Kandemir V, Allaire RB, Jolly JT, Debski RE,McMohan PJ. The Relationship between the orientation of the glenoid and tears of therotator cuff. JBJS. 2006; 88 (8) Aug: 1105-09.

[6] Poppen NK, Walker PS. Normal and abnormal motion of the shoulder. Journal ofBone and Joint Surgery. 1976; 58A: 195-201.

[7] Mamatha T, Pai SR, Murlimanju BV, Kalthur SG, Pai MM, Kumar B. Morphometry of Glenoid Cavity. Online J Health

[8] Allied Scs. 2011;10(3):7

[9] Neeta Chhabra , Suraj Prakash, B K Mishra. An Anatomical Study of Glenoid Cavity: Its Importance in 


\section{International Journal of Science and Research (IJSR) \\ ISSN (Online): 2319-7064}

Index Copernicus Value (2013): 6.14 | Impact Factor (2015): 6.391

Shoulder Prosthesis. Int J Anat Res 2015, Vol

3(3):1419-24. ISSN 2321- 4287

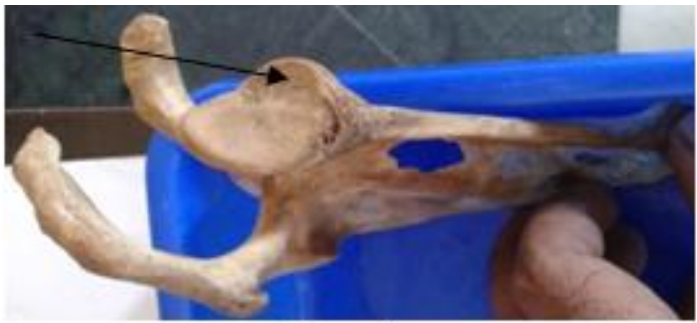

Figure la

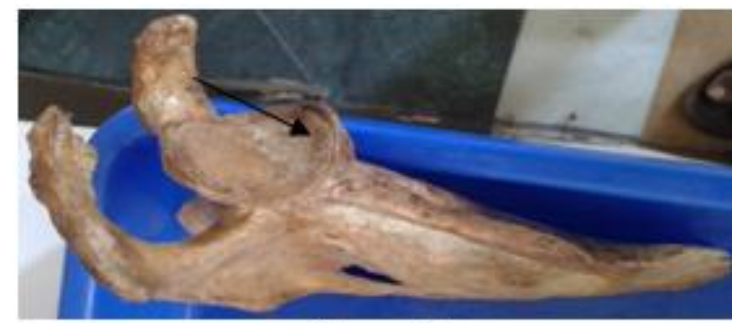

Figure lb

Figure 1a \& 1b: Glenoid Cavity Showed deep rough non articular area

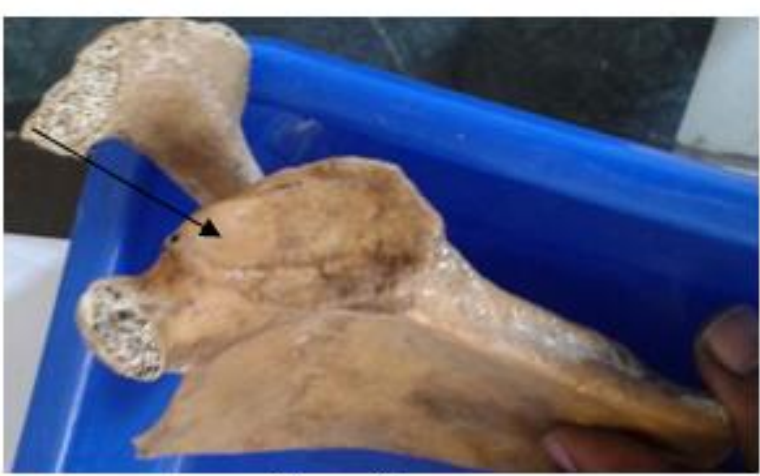

Figure 2a

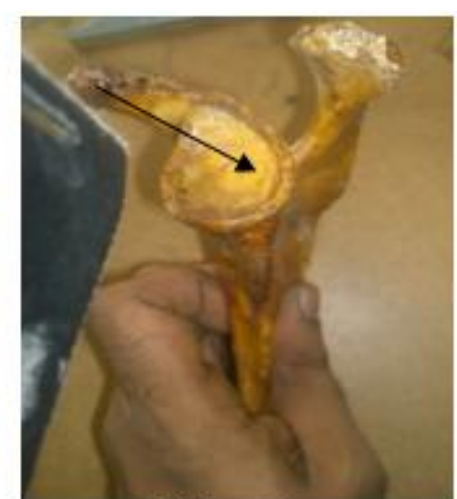

Figure 2b

Figure 2a \& 2b: Glenoid Cavity showing well defined articular facet within the articular area

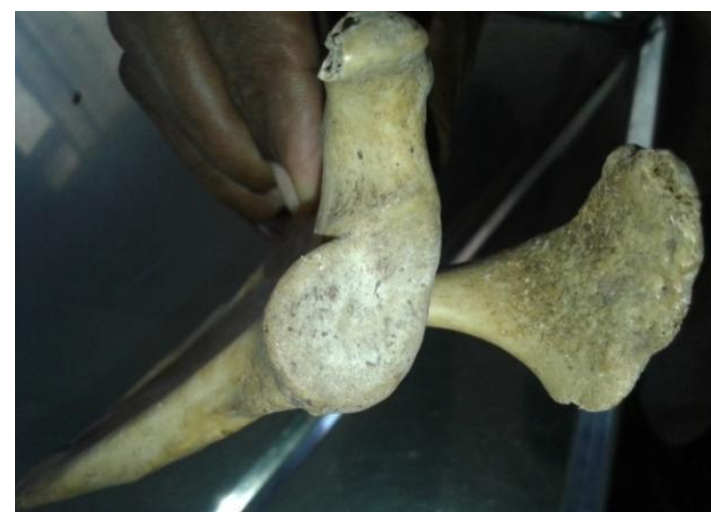

Figure 3: Entire Glenoid articular surface was rough not being lined by hyaline cartilage

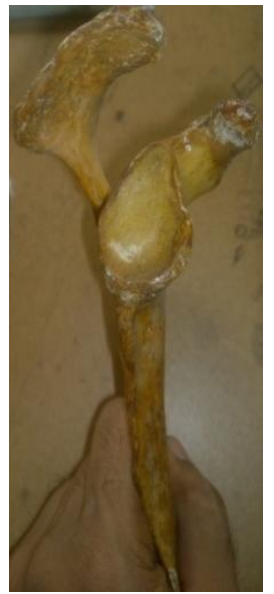

Figure 4: Showing smallest Glenoid Cavity

Volume 5 Issue 6, June 2016 www.ijsr.net

Licensed Under Creative Commons Attribution CC BY 


\section{International Journal of Science and Research (IJSR)}

ISSN (Online): 2319-7064

Index Copernicus Value (2013): 6.14 | Impact Factor (2015): 6.391

Figure 5: Showing Largest Glenoid Cavity

Volume 5 Issue 6, June 2016 www.ijsr.net

Licensed Under Creative Commons Attribution CC BY 